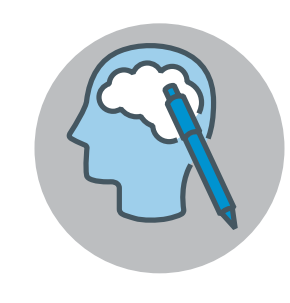

EDITORIAL

Billy Tringali

Emory University
Health Promotion, Collaboration, and Outreach: Creating Space for Health Literacy at a Specialized, Academic Research Library

\section{Principles of partnerships}

$\mathrm{I}$

n the current American cultural climate-living through the COVID-19 pandemic - the ability to engage with and understand health resources is more important than ever.

Health literacy is a complex topic that broadly describes an individual's ability to process health information and use it to make sound medical choices. Many public libraries are currently engaged in health literacy work, as it falls easily within their scope of serving their communities (Flaherty and Miller 2016). Many academic librarians believe university libraries should be doing more to promote health literacy (Duhon and Jameson 2013).

The American College Health Association states that "the purpose of health promotion in higher education, as a field, is to support student success. Colleges and universities have a duty to help members of their community develop skills to optimize their well-being and to establish environments where health and well-being are recognized as critical components of students' ability to learn, work, enjoy, and contribute to the community" (American College Health Association 2019). Libraries, as places embedded in our communities, filled with information and information professionals, make an ideal space for this overarching national mission. Academic librarians can cite national support for engaging in health promotion activities to request time to work on these types of projects. Health literacy stands as target for collaboration. "As health literacy is a cross-cutting issue, addressing it should involve collaborations among a wide range of professionals" (Shipman et al. 2016, 206).

This paper connects academic librarians to the concepts of health literacy and health promotion through examples of collaboration with health experts, and turning an academic library into a built environment that facilitates the growth of health literacy skills.

\section{Brief Definitions: Health Literacy and Health Promotion}

The Committee on Health Literacy states "health literacy skills are needed for dialogue and discussion, reading health information, interpreting charts, making decisions about participating in research studies, using medical tools for personal or familial health care...." (Nielsen-Bohlman et al. 2004, 31). But what does health literacy entail? Nielsen-Bohlman et al. report that the Committee on Health Literacy used the NLM definition in their 2004 book Health Literacy: A Prescription to End Confusion (31-32). Health literacy can be defined as 
The degree to which individuals have the capacity to obtain, process, and understand basic health information and services needed to make appropriate health decisions" (Ratzan and Parker 2000). In their piece on outreach for medical librarians, authors Parker and Krebs (2005) alter the wording of that definition to state that that health literacy is "the ability to obtain, process, and understand basic information and services needed to make appropriate decisions regarding health (S81).

Building from this definition, I approach health literacy from a health promotion perspective. In his brief article detailing the differences between health literacy and health promotion, Thomas Abel (2008) states:

Health promotion approaches do not focus on illness experiences or optimal use of medical services. In health promotion the focus usually is much broader and emphasizes healthy general living conditions and people's chances to live healthy lives. Moreover, health promotion calls for improving the resources people need in order to be active for their health, their own personal health, the health of their families and communities, including the power to change things for the better ... . In this perspective, health literacy refers to people's knowledge about how health is maintained and improved in every day life .... Health literacy also includes the skills to obtain and use appropriate knowledge about health and its determinants (169-170).

Essentially, from the perspective of health promotion, health literacy empowers individuals to improve their own health and the health of their communities through resource access and education.

\section{Initial Steps-Making a Strategic Collaboration}

Emory University is a large, private university with eleven schools and colleges, with a total enrollment of over 15,000 students in 2019 (Emory University "Facts and Figures" ). In relation to health promotion, Emory University notes on its website (under "Social Impact") that it serves its global community through public health. "The university has myriad partnerships and programs-involving experts in public health, medicine, business, and lawdesigned to extend and improve lives in the US and countries around the world" (Emory University "Social Impact"). In the summer of 2019, I started working as the law librarian for outreach at the Hugh F. MacMillan Law Library, and quickly began (/Academic librarians can cite national support for engaging in health promotion activities to request time to work on these types of projects. Health literacy stands as target for collaboration. $)$ attempts to establish my own partnerships with experts in public health, Emory University's Office of Health Promotion..

Joyce Lindstrom and Diana Shonrock's 2006 work on successful collaboration between librarians and faculty argues there are "four behaviors essential for successful collaborative teaching partnerships: shared understood goals; mutual respect, tolerance, and trust; competence for the task at hand by each of the partners; and ongoing communication" (19). However, Thacker and Laut (2018) argue there is an uncertainty around how much collaboration is needed for library instruction partnerships, stating that "despite the potential in collaboration, the literature has been somewhat ambivalent over the extent to which cooperation is necessary" (287). They follow this up with discussions of whether information literacy instruction should be "an embedded liaison or team-teaching model for individual courses, or a thoughtful one-shot library session," requiring many institutions to adopt a more flexible approach (287). Additionally, the researchers highlight the importance of a first impression that demonstrates eagerness to collaborate (291). 
Mygind and Bentsen (2015) argue that, "even when given a commonly shared system of expression, people ... inhabit different worlds and therefore are not able to understand each other. In interdisciplinary work, where people have different horizons and terminologies, misunderstandings and conflict are therefore likely to occur" (122). From this, it can be argued that a certain level of humility must be accepted by librarians when approaching interdisciplinary collaboration. Health literacy experts, health promotion experts, and librarians come from a variety of backgrounds, and can fill in the gaps in each other's skills, knowledge, and access to students. Collaboration is a blending of expertise combined with an ability to bend to someone's greater knowledge, while still ensuring all inputs from all backgrounds are addressed. In my assessment, the best collaborations stand on four tenets: flexibility, respect, enthusiasm, and humility.

After completing this research, I drafted a strategy for initial collaboration with the Office of Health Promotion:

- Be open to any level of partnership

- Respect the time and expertise of the potential partner

- Express genuine enthusiasm for the potential collaboration

- Be humble in your own knowledge and open to learning

Before reaching out to the Office of Health Promotion, I investigated what types of health-related materials already existed within the library space. MacMillan Law Library has extensive resources relating to the law, legal theory, and how to pass law school classes, but had few resources relating to building resilience and stress management, and no permanent resources dedicated to sexual health, nutrition, or sleep hygiene. Books

(/The best collaborations stand on four tenets: flexibility, respect, enthusiasm, and humility. $)$ related to stress, such as How to Be Happy In Law School, were shelved on the fourth floor, in between books about securing a job and studying for exams. The library hosted several destress-based events for students throughout the school year, the most important one being MacMillan Library's biannual

destress event, Stress Busters. Arriving to my initial meeting with the Office of Health Promotion with definitive answers for what exactly the library was already doing as it related to health promotion built a foundation from which ideas and a potential partnership could grow.

During our second meeting, I insisted that the library was open to any level of collaboration, stating MacMillan Library would be grateful for any collaboration the Office of Health Promotion would be interested in, ranging from recommendations of resources supporting health promotion, through full involvement in Stress Busters. By following the steps laid out in my collaboration strategy, the first meeting between the Hugh F. MacMillan Law Library and the Office of Health Promotion was a great success.

\section{Flexibility and Endless Opportunity}

I first reached out to the Office of Health Promotion in September of 2019. My goal was to be as enthusiastic and flexible as possible in fostering a relationship with this office. I stated in my initial email that I was interested in forging a connection between our departments, interested in the types of resources they created, and interested in learning more about their services and resources.

Unbeknownst to the law library, the Office of Health Promotion had already done research on Emory Law's students in 2017. This research indicated that law students rated themselves physically healthier than the rest of campus, but felt that they experienced more stress and high-risk alcohol use (Amposta et al. 2018). This research was done without collaboration from the law library, and 
its discovery was an immediate benefit of my first meeting with the Office of Health Promotion. Simply by being open to working with the Office of Health Promotion, the law library was given immediate access to research that had already been done on our patron population.

This research indicated students needed resources on mental health and safe drinking habits, and the Office of Health Promotion agreed to provide dozens of booklets and health resources relating to various issues so that the MacMillan Library could make them directly accessible to students. A small table was set next to the circulation desk, near an area dedicated to a community puzzle, and this space became a permanent home for grab-and-go health promotion resources. As simple as this gesture might seem, Parker and Krebs (2005) argue "people of all literacy levels prefer materials that are simple and easy to understand." (S83). This area soon became a center of great activity, with resources needing to be replaced several times each week. By this metric, the grab-and-go resources were a success.

This setup was later spotted and commented on by a member of Emory Law School's Student Services Department, who noted they had a number of destress-related booklets they would be happy share with the library. Following the set guideline of being flexible to any and all levels of partnership, I accepted, and as a gesture of reciprocity forged a relationship between the Office of Health Promotion and the Emory Law School's Office of Student Services. This connection led to a partnership between all three groups, in which the Office of Health Promotion wanted to provide safe-sex supplies and booklets on sexual education to MacMillan Library, but the library lacked space for both. Student Services offered to accept the safe-sex supplies while MacMillan Library accepted the resources, allowing all three partners to benefit.

Physically designating space which gave students access to health resources helped create a built environment in MacMillan Library, as evidenced by the speed at which health promotion resources were taken by students and needed to be replaced.

The "built environment" is a term used in public health to describe the relationship of health to the environment (National Center for Environmental Health 2011). Though it is more often used to describe the physical space of a city, Health Literacy: The Solid Facts (produced by the WHO), argues that "The interaction of settings, people and professionals is crucial" in developing health literacy (Kickbusch et al. 2013, 27). Using the term from a health promotion perspective, the library becomes a built environment which promotes and facilitates wellness literacy. By creating physical space for wellness resources, libraries can change the built environment to facilitate students engaging with resources and through that interaction, build wellness literacy.

From both a public health and a librarianship perspective, the idea of a built environment is not a new one. As much as librarians advocate that libraries are infinitely more than their spaces, and they most definitely are, it needs to be highlighted that the library is still often used as a physical space, and this physical space is essential to the health of the library's community. The 2012 paper "Use of Library Space and the Library as Place" claims that "public libraries are used as meeting places to a great extent" (Aabø and Audunson 2012 , 139). A Canadian piece discussing how users construct and behave in library spaces notes that patrons construct the library as "a truly public place, a place where they are free to both participate in and shape the services offered. In this study, the public library emerged as a modem day ... main square, a community destination where people gather to read, share information, and interact with one another, without the constraints imposed by other quasipublic North American spaces" (McKechnie et al. 2004, 50). Library spaces are 
unique because patrons interact with them so intensely, and this interactive environment makes the library an ideal place for health promotion. As Parker and Kreps (2005) argue "effective health communication is interactive and adaptive, utilizing many different channels of communication and operating across a number of different contexts" (S84). Even in discussions of architectural design, arguments for built environments are made. Haiping Li's 2017 work, "Built to Succeed: Sustainable Learning Environment at UC Merced Library," affirms that the physical design of the "Library is built to support active and constructive learning through its sustainable design as an open, collaborative and welcoming learning environment and it has become a sustainable environment that supports sustainable learning for the future" (178). MacMillan Library created a built environment in a number of ways, most notably through the dedication of space to health resources.

To help create a built environment, I began creating displays to highlight health-related resources, giving visibility to resources students might not otherwise engage with. I also began to incorporate health information in the bi-monthly bathroom newsletter. Both of these practices are supported by author Mary Flaherty (2018) in her book Promoting Individual and Community Health at the Library: "Displays are another opportunity for promoting health information, such as the use of simple plastic sleeves to display health news items in restrooms" (59).

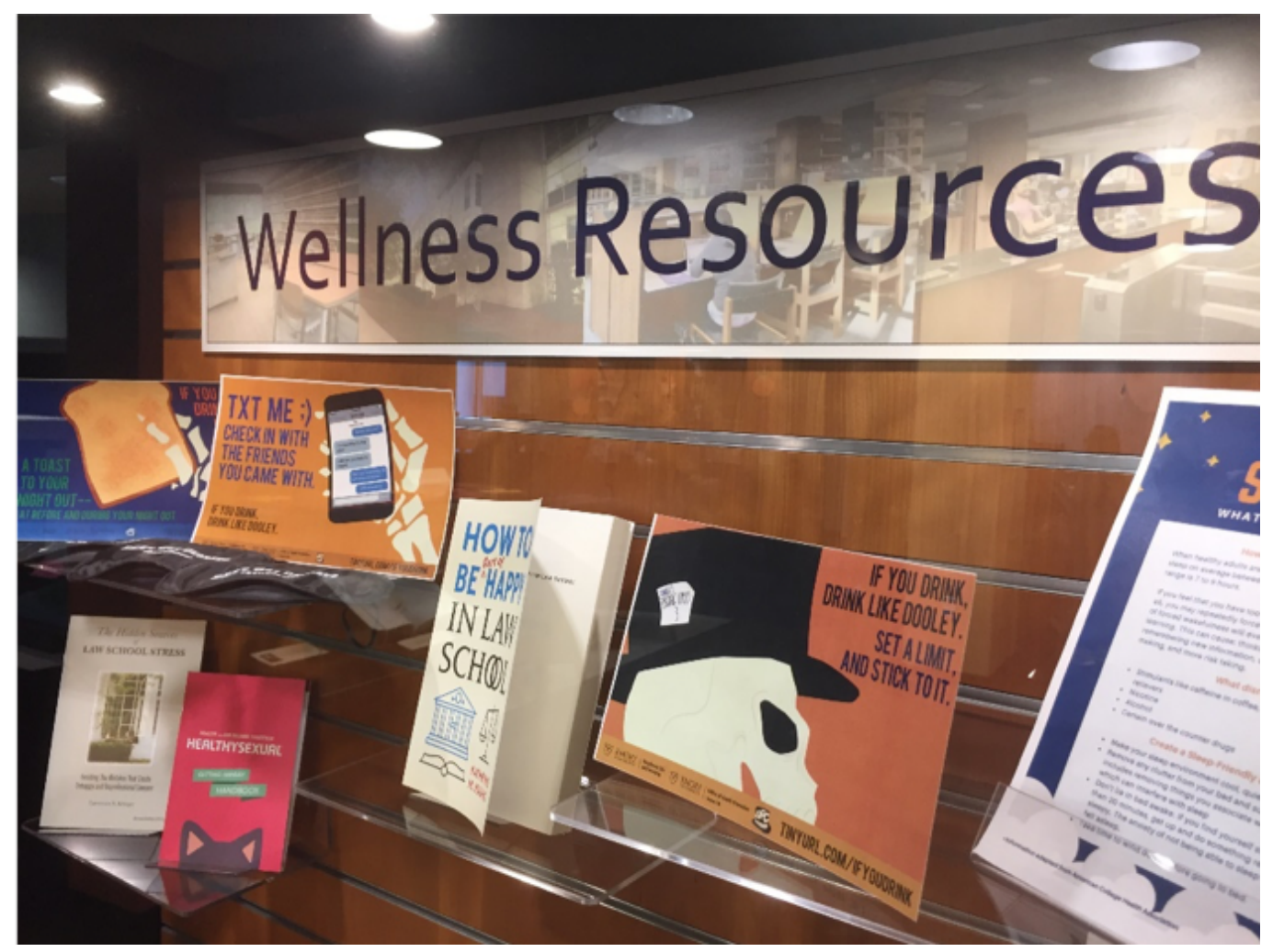

Figure 1. A wellness resources display put up before Stress Busters.

For further assessment, I administered a two-question survey to students asking if they would like to see further health resources at the library. The survey was administered in person via a digital form on a laptop, near the entrance to the library, and collected no personal data about students. Students were asked "Would you be interested in seeing MacMillan Library build a wellness resource collection?" and were able to respond Yes or No. Of the 84 students who responded, 100 percent stated they would be interested in having a permanent collection of wellness resources. If the answer to the first 
question was Yes, the next item prompt-_"I would be interested in seeing books about" - offered numerous options students could select without limit. These options were: nutrition and/or cooking, sexual health, mental health, sleep hygiene, resilience or ability to deal with challenge, destress methods, substance abuse, alcohol education, and general wellness. Most students stated they wanted resources on nutrition (58\%), followed by mental health (54\%), and then sleep hygiene (54\%). This surveying of students paved the way to dedicate shelving space to a new collection of books on the library's second floor, the same floor that holds booklets and resources on health promotion. The funding for these new materials was acquired through a grant I applied for through the Office of Health Promotion, further strengthening our relationship and collaborations in the creation of this built environment. That these books were placed on the same floor as our other health resources, instead of in the bookstacks elsewhere in the library, further facilitated the creation of a built environment.

The collaboration between the MacMillan Library and the Office of Health Promotion, and the creation of a built environment at MacMillan Library, led students to be exposed to more health literacy information. In response to this collaboration and the creation of a built environment, students rapidly claimed health resources and demonstrated overwhelming interest in healthrelated books being procured. Within the first two weeks that dozens of health resource pamphlets were placed in the library, I had to request more from the Office of Health Promotion, marking this collaboration a great success. Beyond resources, this partnership with the Office of Health Promotion lead to more unique, health literacy-focused programming at Stress Busters, which students responded to positively. The Office of Health Promotion set up a table, staffed by two team members, offering health resources to students. This table was visited by more than 120 students over the course of the two evenings the table was staffed. In the long run, I hope this collaboration with the Office of Health Promotion, and the built environment that emerged from it, will benefit the lives of the students MacMillan Library serves. In the short term, this built environment has facilitated students' engagement with health resources, and through that interaction the library has built health literacy.

\section{Conclusion}

Academic libraries stand as a perfect venue to forward the necessary mission of health promotion. I hope that, by having laid out the guidelines I followed for successful outreach, I have inspired potential outreach plans in other libraries. I also hope that, in describing the growth that emerged from simply dedicating space in MacMillan Library to health resources, this paper can encourage librarians that participate in outreach and engagement to build partnerships with campus health offices and establish a built environment in their own library. Future research in this overlap of health promotion and librarianship may involve in-depth interviews with students over the course of a semester, and working with them and the Office of Health Promotion to establish a stronger timeline when health literacy programming may be most effective. 


\section{References}

Abel, T. 2008. "Measuring Health Literacy: Moving Towards a HealthPromotion Perspective." International Journal of Public Health 53: 169-170.

American College Health Association. 2019. "Standards of Practice for Health Promotion in Higher Education." ACHA Guidelines (Fourth Edition). ACHA.

Amposta, J., L. Greene, A. Patterson, E. Odunaiya, M. N. CarmanMcClanahan, E. Lyles, D. Zhong, K. Chiseri, B. Benton, W. Swan, M. Passonno, and J. Duncan. 2018. "2017 Emory University National College Health Assessment Summary." Emory University Office of Health Promotion.

Aabø, S., and R. Audunson. 2012. "Use of Library Space and the Library as Place." Library and Information Science Research 34, no. 2: 138-149.

Duhon, L., and Jameson, J. 2013. "Health Information Outreach: A Survey of US Academic Libraries, Highlighting a Midwestern University's Experience." Health Information and Libraries Journal 30, no. 2: 121-137. https://doi-org.proxy2.library.illinois.edu/10.1111/hir.12017

Emory University. N.D. "Social Impact." Emory University. Accessed February 10, 2021. https://brand.emory.edu/source-book/narratives/social-impact.html

Emory University. N.D. "Facts and Figures." Facts and Figures. Accessed May 26, 2020. https://www.emory.edu/home/about/factsfigures/index.html

Flaherty, M. G. 2018. Promoting Individual and Community Health at the Library. ALA Editions.

Flaherty, Mary Grace, and David Miller. 2016. "Rural Public Libraries as Community Change Agents: Opportunities for Health Promotion." Journal of Education for Library and Information Science 57, no. 2 (Spring): 143-50. doi:10.12783/issn.2328-2967/57/2/6.

Kickbusch, Ilona, Jürgen M. Pelikan, Franklin Apfel, and Agis D. Tsouros. 2013. Health Literacy: The Solid Facts. World Health Organization..

Li, Haipeng. 2017. "Built to Succeed: Sustainable Learning Environment at UC Merced Library." Library Management 38, no. 2/3: 175-180.

Lindstrom, Joyce and Shonrock, Diana D. 2006. "Faculty-Librarian Collaboration to Achieve Integration of Information Literacy." Reference and User Services Quarterly 46, no. 1: 18-23.

McKechnie, L. E. F., P. K. French, G. R. Goodall, M. Kipp, D. L. Paquette, and J. L. Pecoskie. 2004. "Covered Beverages Now Allowed: Public Libraries and Book Superstores." Canadian Journal of Information and Library Science 28, no. 3: 39-51.

Mygind, L., A. K. Hällman, and P. Bentsen. 2015. “Bridging Gaps between Intentions and Realities: A Review of Participatory Exhibition Development in Museums." Museum Management and Curatorship 30, no. 2: 117-137. http:/ / doi.org/10.1080/09647775.2015.1022903

National Center for Environmental Health, Division of Emergency and Environmental Health Services. 2011. "Impact of the Built Environment on Health." Center for Disease Control. https://www.cdc.gov/nceh/ publications/factsheets/impactofthebuiltenvironmentonhealth.pdf

Nielsen-Bohlman, L., A. M. Panzer, and D. A. Kindig, (Eds.). 2004. Health Literacy: A Prescription to End Confusion. National Academies Press.

Parker, R. and G. L. Kreps. 2005. "Library Outreach: Overcoming Health Literacy Challenges." Journal of the Medical Library Association: JMLA 93 no. 4 Suppl: S81-S85. 
Ratzan, S. C., and R. M. Parker "Introduction." In C. R. Selden, M. Zorn, S. C. Ratzan, and R. M. Parker. (Eds.). 2000 "National Library of Medicine Current Bibliographies in Medicine: Health Literacy." NLM Pub. No. CBM 2000-1. Bethesda, MD: National Institutes of Health, U.S. Department of Health and Human Services.

Shipman, Jean, Erica Lake, and Alice Weber. 2016. "Improving Health Literacy: Health Sciences Library Case Studies." Reference Services Review 44: 206-214. doi: 10.1108/RSR-03-2016-0022.

Thacker, Mara L., and Julie R. Laut. 2018. "A Collaborative Approach to Undergraduate Engagement." Portal: Libraries and the Academy 18, no. 2: 283-300. doi:10.1353/pla.2018.0016.

\section{Author Details}

Billy Tringali, Law Librarian for Outreach, Emory University:

william.tringali@emory.edu 